\title{
Effects of social learning on the acquisition of discriminatory keypecking in hens
}

\author{
C. J. NICOL and S. J. POPE \\ University of Bristol, Bristol, England \\ (Vincent LoLordo, Sponsor)
}

\begin{abstract}
In Experiment 1, adult laying hens observed conspecific demonstrators pecking one of two keys for food reward during 10 daily sessions. Control groups observed untrained conspecifics or no other bird over the same period. In subsequent tests in the response chamber, hens that had observed demonstrators performed more keypecks than hens from control groups, and they showed significant discrimination in favor of the key that their demonstrator had pecked. In Experiment 2, hens observed either conspecific demonstrators or an artificial rod "peck" one of two keys. In subsequent tests, hens that had observed demonstrators again discriminated in favor of the key their demonstrator had pecked. Hens that had observed rod "pecking" made no keypecks in the response chamber. The exact mechanisms involved remain to be elucidated.
\end{abstract}

The behavior of individuals of many species is strongly influenced by the presence and behavior of conspecifics. Galef (1988) proposed the term social enhancement to refer to all social influences on the performance of established responses. The term social learning, then, refers to cases in which social interaction facilitates the acquisition of a novel pattern of behavior. It is commonly assumed that learning by observation and imitation of conspecifics has considerable adaptive value (e.g., Zentall \& Galef, 1988), and is therefore common, but rigorous laboratory demonstrations are necessary to exclude other mechanisms. A number of laboratory studies have shown that observation of a trained conspecific (demonstrator) can facilitate subsequent response acquisition, in both rats and pigeons, of simple instrumental tasks (e.g., Palameta \& Lefebvre, 1985; Zentall \& Levine, 1972) and discriminatory instrumental tasks (e.g., Biederman \& Vanayan, 1988; Edwards, Hogan, \& Zentall, 1980; Heyes \& Dawson, 1990). Laboratory studies of social learning have been undertaken in some other species (e.g., budgerigars; Galef, Manzig, \& Field, 1986), but there is a need for a broader knowledge of species differences in this area. There has been very little investigation of social learning in the domestic fowl. Two studies have purported to show that domestic fowl might learn new responses by imitation. Cronhelm (1970) provided some evidence that observation of a trained demonstrator facilitated the acquisition of an instrumental discrimination task in domestic chicks, but in this experiment the observer chicks were given more time to adapt to the experimental setup than were the demonstrators with which they were compared. Johnson, Hamm, and Leahey (1986) studied the acquisition of a simple instrumental keypeck response in adult chickens. Chickens that had observed a demonstrator responded earlier and more fre-

The authors' mailing address is Department of Animal Husbandry, Langford House, Bristol, BS18 7DU, U.K. quently on a subsequent autoshaping test than did chickens that had only observed a positive correlation between keylight and food hopper operation or chickens that had had no observational experience. However, this experiment did not include a control for the simple presence of another chicken during the observation sessions. Fear reduction resulting from the presence of a conspecific may have increased observer attention to keylights during the observation sessions or may have facilitated performance during the autoshaping test.

The aim of the experiments reported here was to ascertain whether social learning played any part in the acquisition of a discriminative learning task in adult hens.

\section{EXPERIMENT 1}

\section{Method}

\section{Subjects}

Thirty-six 24-week-old naive Isabrown hens were used as subjects. Four hens were assigned randomly to the role of demonstrators; the remaining 32 were observers and controls. The hens were housed in pairs in conventional battery cages with a spatial allowance of $750 \mathrm{~cm}^{2}$ per bird. $\mathrm{Ob}$ servers were not housed with or adjacent to their own demonstrators. Food was removed $4 \mathrm{~h}$ prior to testing and replaced $1 \mathrm{~h}$ after each daily session.

\section{Apparatus}

A two-chamber box was constructed with solid metal sides, a wire mesh floor, a clear Perspex partition between the chambers, and a hinged clear Perspex lid. The "response chamber" contained two keys, one light directly above each key, and a metal door that opened outwards to give access to a food hopper whenever a subject made a correct response. The left-hand key and light were colored green (key A); the right-hand key and light were colored red (key B). The "observation chamber," from which each subject observed its demonstrator's behavior, was featureless.

A BBC Master computer running Spider real-time control language controlled the equipment. Keypeck data were automatically recorded by the same system, but, during observer testing, recordings of the behavior of subjects in the response chamber were also taken by overhead video.

\section{Procedure \\ Demonstrator training. Demonstrators were given an initial pretrain- ing session in which the door to the feed tray was automatically opened}


for 10-sec and closed for 5-sec periods for a total of $5 \mathrm{~min}$. The demonstrators were then given six daily sessions in which they were trained by conventional methods to peck either key A or key B to obtain access to the food hopper. By Day 6 all demonstrators reliably pecked the key four times for each reinforcement of 10-sec access to food. Ten reinforcements were allowed each session.

Observer training. Observers were randomly allocated to one of the eight following groups: DA1, Demonstrator 1 pecking key A; DA2, Demonstrator 2 pecking key A; DB3, Demonstrator 3 pecking key B; DB4, Demonstrator 4 pecking key B; U5, Untrained Bird 5 in response chamber; U6, Untrained Bird 6 in response chamber; N7, no bird in response chamber; and N8, no bird in response chamber.

Daily observation sessions for 10 days were given, with an additional observation session after the first observer test. The observers were placed in the observation chamber and allowed to watch demonstrators obtain 5 reinforcements each day. As demonstrators pecked the correct key, the light above that key was illuminated for $0.5 \mathrm{sec}$. Observers from Groups $\mathrm{U}$ and $\mathrm{N}$ were placed in the observation chamber for 2 min each day. This corresponded to the average amount of time observers in Groups DA1-4 spent each day in the chamber. The order in which the birds were used was systematically altered each day both within groups, to control for any changes in demonstrator performance within the session, and between groups to control for differences in length of food deprivation as the test progressed.

Observer tests. The observers were placed individually in the response chamber, with the observation chamber left empty, and their behavior was recorded continuously for $10 \mathrm{~min}$ by video. The videotapes were analyzed to ascertain the number of pecks made to parts of the chamber that were not recorded by computer. A bird was defined as facing the front panel if its head-body axis was within $30^{\circ}$ each side of a perpendicular line from the front panel. Responses on both keys were rewarded with 10-sec access to the food hopper on a fixed ratio (FR)1 schedule. In order to assess whether experience in the response chamber might increase subsequent attention to the demonstrator, the observers were given one further observation session on Day 11, followed by another 10-min session in the response chamber on Day 12.

\section{Results}

\section{Demonstrator Behavior During Observation Sessions}

All demonstrators showed perfect discrimination throughout the experiment. Due to computer error, keypeck data for Demonstrator 4 on Days 4 and 8 were missing. A repeated measures analysis of variance, with daily session taken as a nonindependent replicate, was used to examine the effects of demonstrator identity and observer order within each session. There were significant differences between demonstrators in time taken to make 4 keypecks $[F(3,739)=16.0, p<.001]$. There was also a significant increase in time to keypeck within each daily session so that the first observer each day observed faster responses than did the fourth observer each day $[F(3,739)=27.3$, $p<.001]$. There was also a significant interaction between these two factors, showing that all demonstrators increased their response time within an observation session but that this was most pronounced in Demonstrator 2.

\section{Observer Behavior During Test 1}

There were a number of differences between the overall behavior of birds that had observed demonstrators (Groups D) and birds that had observed either an untrained bird (Groups U) or no bird (Groups N). Analysis of variance followed by Fisher's LSD showed that birds that had observed a demonstrator spent more time facing the keys $[F(2,29)=9.3, p<.001]$ and pecking the feeder door $[F(2,29)=4.4, p<.05]$ than did birds that had observed no bird. Birds that had observed a demonstrator also performed more keypecks $[F(2,29)=3.3, p<.05]$ than birds that had observed an untrained bird or no bird. There were no significant differences between groups in the number of pecks delivered to the lights or to the walls of the cage. These results are summarized in Table 1.

Since Demonstrator 1 responded consistently faster than Demonstrator 2, it was hypothesized that the responses of the birds from Group DA1 might differ from those of the birds from Group DA2. However, a two-tailed $t$ test showed that there was no significant difference between these two groups in the time spent facing the keys. Similar analyses showed no significant differences in number of pecks delivered to the lights, to the wall of the chamber, to the feeder, or to the keys. Similarly, Demonstrator 4 responded consistently faster than Demonstrator 3, but there were no significant differences in the behavior of birds from Groups DB3 and DB4, which had observed each demonstrator.

To assess whether observers had developed a preference for pecking at the same key as their demonstrators, a discrimination ratio (DR) was calculated for each bird by dividing the number of pecks to key $A$ by the total number of pecks to either key made by that bird during the test session. Eight out of 16 birds in Groups $U$ and $N$ performed 1 or more keypecks. The overall DR for these birds was $0.51(S D=0.12)$, with 3 birds pecking more at key A, 3 birds more at key B, and 2 with an equal number of pecks at both. This demonstrated no significant bias for either key. The mean DR for Groups DA1 and DA2 was $0.66(S D=0.2)$; for Groups DB3 and DB4, it was $0.33(S D=0.2)$. This difference in DR was significant $[t(14)=3.04, p<.01$, two-tailed test $]$. There were no significant differences in discrimination ratio between Groups DA1 and DA2 or between Groups DB3 and DB4.

Although, in the number of pecks made to the lights, there was no overall significant difference between birds that had observed demonstrators and birds that had observed untrained birds or no birds, a DR was again calculated for each bird in Groups DA and DB, this time by dividing the number of pecks made to the light above key $\mathrm{A}$ by the total number of pecks made to both lights by that bird during the test session. There was no significant difference in the mean DR for Groups DA1 and DA2 $(\mathrm{DR}=0.51, S D=0.3)$ or for Groups DB3 and DB4 $(\mathrm{DR}=0.30, S D=0.25)[t(14)=1.54, p>.05]$.

Table 1

Behavior of Observers During First Test

\begin{tabular}{|c|c|c|c|c|c|c|}
\hline & \multicolumn{2}{|c|}{$\begin{array}{c}\text { Watched } \\
\text { Demonstrator } \\
(n=16)\end{array}$} & \multicolumn{2}{|c|}{$\begin{array}{c}\text { Watched } \\
\text { Untrained } \\
(n=8)\end{array}$} & \multicolumn{2}{|c|}{$\begin{array}{c}\text { Watched } \\
\text { No Bird } \\
(n=8)\end{array}$} \\
\hline & $M$ & $S D$ & $M$ & $S D$ & $M$ & $S D$ \\
\hline Time facing key (minutes) & $6.3^{\mathrm{a}}$ & 0.4 & 5.0 & 0.6 & $3.3^{\mathrm{b}}$ & 0.6 \\
\hline Pecks to walls & 18.3 & 3.2 & 27.6 & 8.1 & 26.5 & 9.7 \\
\hline Pecks to feeder door & $21.6^{\mathrm{a}}$ & 5.3 & 8.7 & 5.5 & $0.6^{\mathrm{b}}$ & 0.3 \\
\hline Pecks to lights & 11.5 & 4.5 & 2.4 & 1.8 & 1.2 & 0.7 \\
\hline Pecks to keys & $6.2^{\mathrm{a}}$ & 2.2 & $0.4^{\mathrm{b}}$ & 0.3 & $0.5^{\mathrm{b}}$ & 0.4 \\
\hline
\end{tabular}

Note-Means with different superscripts differ at $p<.05$. 
Table 2

Behavior of Observers During Second Test

\begin{tabular}{|c|c|c|c|c|c|c|}
\hline & \multicolumn{2}{|c|}{$\begin{array}{c}\text { Watched } \\
\text { Demonstrator } \\
(n=16)\end{array}$} & \multicolumn{2}{|c|}{$\begin{array}{c}\text { Watched } \\
\text { Untrained } \\
(n=8)\end{array}$} & \multicolumn{2}{|c|}{$\begin{array}{c}\text { Watched } \\
\text { No Bird } \\
(n=8)\end{array}$} \\
\hline & $M$ & $S D$ & $M$ & $S D$ & $M$ & $S D$ \\
\hline Time facing key (minutes) & 5.4 & 0.6 & 3.3 & 0.5 & 4.4 & 0.5 \\
\hline Pecks to walls & 7.9 & 1.6 & 2.9 & 1.3 & 17.2 & 6.5 \\
\hline Pecks to feeder door & 4.3 & 2.1 & 1.4 & 1.1 & 4.7 & 2.9 \\
\hline Pecks to lights & 0.7 & 0.4 & 0.0 & 0.0 & 0.7 & 0.4 \\
\hline Pecks to keys & $1.4^{\mathrm{a}}$ & 0.5 & $0.0^{\mathrm{b}}$ & 0.0 & $0.0^{b}$ & 0.0 \\
\hline
\end{tabular}

Note-Means with different superscripts differ at $p<.05$.

\section{Observer Behavior During Test 2}

After one further observation session on Day 11, the birds were retested in the same apparatus on Day 12. The overall behavior of birds that had observed demonstrators (Groups DA and DB), birds that had observed an untrained bird (Groups $U$ ), and birds that had observed no bird (Groups $N$ ) is shown in Table 2. Analysis of variance showed that there were significant differences between these groups $[F(2,29)=3.3, p<.05]$. Fisher's LSD revealed that birds that had observed a demonstrator performed more keypecks than did birds from either of the other groups (Table 2). There were no other significant differences between the groups.

The most striking difference between the results of Tests 1 and 2 was that, although there was no difference in the overall time the birds spent facing the keys, all pecking activity showed strong and significant declines (pecks to feeder, $t=2.6, p=.01$; to lights, $t=2.4, p=.02$; to wall, $t=3.3, p<.01$; to keys, $t=2.0, p=.05$ ). The mean discrimination ratios also declined. For Groups DA1 and DA2, the mean DR was $0.56(S D=$ $0.11)$; for Groups DB3 and DB4, it was $0.46(S D=0.3)$.

\section{EXPERIMENT 2}

Method
Subjects and Apparatus
Eighteen 24-week-old naive Isabrown hens were used as subjects. Two
hens were assigned randomly to the role of demonstrators; the remain-
ing 16 were observers or controls. The hens were housed as in Experi-
ment 1 , and the same apparatus was employed.

\section{Procedure}

Demonstrator training. Since no apparent bias toward either key was shown in Experiment 1, both demonstrators were trained to peck key A. The training procedure was as described for Experiment 1.

Observer training. Observers were randomly allocated to one of the following four groups: DA1, Demonstrator 1 pecking key A; DA2, Demonstrator 2 pecking key A; RA1, rod "'pecking'" key A; and RA2, rod "pecking"' key $\mathrm{A}$.

Ten daily observation sessions were given, with the experimenter sitting adjacent to the response chamber throughout each session. Observers from Groups DA1 and DA2 were placed in the observation chamber and allowed to watch demonstrators obtain 5 reinforcements per day. As demonstrators pecked key $\mathrm{A}$, the light above that key was illuminated for $0.5 \mathrm{sec}$. Observers from Groups RA1 and RA2 were allowed to watch a red rod, with a pointed end (length, $15 \mathrm{~cm}$; diameter, $1 \mathrm{~cm}$ ), "peck" the correct key on an FR4 schedule. The rod was operated by the experimenter. Great care was taken that the experimenter maintain the same position during the training of all four groups. The rod's "pecking" opened the door to the food hopper in the response chamber for five 10-sec periods each day. As the rod "pecked" key A, the light above that key was illu- minated for $0.5 \mathrm{sec}$. The order in which birds were used was systematically altered each day both within and between groups, as in Experiment 1.

In this experiment, all the observers were videoed during the observation sessions. From the videotapes, the orientation of all subjects was examined and a subjective assessment was made of the number of correct pecks, or rod "pecks," apparently observed during each session. Observers oriented within $30^{\circ}$ to the left of a perpendicular line from the front panel to $90^{\circ}$ to the right were taken as apparently observing keypecks, provided they were not preening or foot pecking.

Observer tests. Observers were placed individually in the response chamber, with the observation chamber left empty, and their behavior was recorded for $10 \mathrm{~min}$. Responses on both keys were rewarded with 10-sec access to the food hopper on an FRI schedule.

\section{Results}

\section{Demonstrator Behavior During \\ Observation Sessions}

Both demonstrators showed perfect discrimination throughout the experiment. Repeated measures analysis of variance was again used to examine the effects of demonstrator identity and observer order within each session. There were significant differences between the demonstrators in time taken to make 4 keypecks $[F(1,338)=14$.14, $p<.001]$, but no significant within session changes in time to keypeck in this experiment $[F(3,338)=1.63, p>.05]$.

\section{Observer Behavior During Observation Sessions}

After analyzing the orientation of observer birds, it was found that there were no significant differences between the number of correct pecks apparently observed by birds in Groups DA1 and DA2 and the number of rod "pecks" apparently observed by birds in Groups RA3 and RA4. The mean number of correct pecks observed by birds in Groups DA1 and DA2 per session was $16.0(S E=0.72)$; the number of rod "pecks" observed by birds in Groups RA3 and RA4 was $14.6(S E=0.74)$.

During the observation sessions, birds from all groups made some pecks to the walls of the observation chamber. Analysis of variance was used to compare the number of pecks to the observation chamber, on each observation day, made by birds from Groups DA1 and DA2 with those made by birds from Groups RA1 and RA2. Birds in Groups DA1 and DA2 made more pecks (13.5, $S E=2.8)$ than birds in Groups RA1 and RA2 $(2.9, S E=$ $0.5)[F(1,130)=9.92, p<.01]$, but there was no effect of day $[F(9,130)=0.4, p>.05]$.

\section{Observer Behavior During Test}

There were considerable differences in the overall behavior of birds that had observed demonstrators (Groups D) and birds that had observed the rod (Groups R). Birds that observed rod "pecking" failed to peck the keys in the test. The use of two-tailed $t$ tests showed that birds that had observed a demonstrator performed significantly more pecks to walls $(t=2.26, p<.05)$ and lights $(t=2.71, p<$ .05 ), but the number of pecks directed toward the keys just failed to reach significance because of marked individual variation within groups $(t=1.81, p<.09)$. There was no difference in the number of pecks directed toward the feeder in this experiment $(t=0.97)$. The mean pecks are shown in Table 3. 
Table 3

Behavior of Observers During Fxperiment 2

\begin{tabular}{llllll}
\hline & \multicolumn{2}{c}{$\begin{array}{c}\text { Watched } \\
\text { Demonstrator } \\
(n=8)\end{array}$} & & \multicolumn{2}{c}{$\begin{array}{c}\text { Watched } \\
\text { Rod } \\
(n=8)\end{array}$} \\
\cline { 2 - 3 } \cline { 5 - 6 } & $M$ & $S D$ & & $M$ & $S D$ \\
\hline Pecks to walls & $3.9^{\mathrm{a}}$ & 1.4 & & $0.0^{\mathrm{b}}$ & 0.0 \\
Pecks to feeder door & 5.1 & 4.2 & & 1.0 & 0.8 \\
Pecks to lights & $1.8^{\mathrm{a}}$ & 0.8 & & $0.0^{\mathrm{b}}$ & 0.0 \\
Pecks to keys & 3.6 & 2.0 & & 0.0 & 0.0 \\
\hline
\end{tabular}

Note-Means with different superscripts differ at $p<.05$.

The mean discrimination ratio for birds in Groups D was $0.71(S D=0.19)$, which was significantly different from the null expectation of 0.51 ( $p<.05$, one-tailed).

\section{DISCUSSION}

Experiments 1 and 2 demonstrated that social learning played a significant role in the acquisition of a discriminative instrumental response in adult hens. The exact mechanism involved remains to be elucidated, but a number of points can be made. First, the presence of an untrained bird during observation sessions had no significant effect on response acquisition, so the results cannot be explained by postulating a simple decrease in isolation-induced fear in some groups. Second, birds that observed the use of a rod to "peck" the key during the observation sessions made no pecks to the keys or lights during subsequent tests in the response chamber. It therefore seems unlikely that the results of Experiment 1 can be explained as observers' learning about stimulus-reinforcer relationships rather than response-reinforcer relationships. Denny, Clos, and Bell (1988) showed that observation of an automatically moving lever signaling food delivery facilitated discriminative learning in the rat. No such facilitation was apparent in the hens in this experiment. However, one difference was that in Denny et al.'s experiment lever movement preceded food delivery to the observers, whereas in this experiment rod "pecking" allowed the observers sight of the food hopper but not access to it. However, this difference in reinforcement obtained during observation training, applied to all groups in our experiments, and it can therefore be concluded that something about the behavior of the demonstrators was important in facilitating response acquisition in observers.

In Experiment 2, it was shown that birds that observed a demonstrator performed more generalized wallpecks to the observation chamber than did birds that observed the rod. This would appear to be an effect of social facilitation. However, in both experiments, birds that had observed demonstrators performed more keypecking in the response chamber than other groups, even though the demonstrator was then absent. Social facilitation is not usually taken to have lasting effects of this kind (Clayton, 1978; Zajonc, 1965).

There are two contending mechanisms which could explain the results obtained in these experiments. First, the hens' attention could have been drawn to either key A or key B in the response chamber by the behavior of the demonstrator. This process is generally called local enhancement, or stimulus enhancement. The fact that hens observing the rod "pecking"' key A did not respond as well as hens that watched a demonstrator does not rule out stimulus enhancement as an explanation of these results. Suboski and Bartashunas (1984) found that an artificial "pecking" arrow did affect the development of subsequent pecking preferences in neonatal chicks, but adult birds may be less influenced by crude models of this type. If the birds made their discriminations because of stimulus enhancement, this could have been done on the basis of either key color or position. Vallortigara and Zanforlin (1988) have shown that in simultaneous discrimination learning chicks rely primarily on the relative position of goal objects and use color to segregate the goal objects as distinct perceptual units. Second, the hens could have copied the exact motor patterns of the demonstrators in the response chamber and learned to make their discriminations by a process of true imitation. Recent studies in other species have attempted to examine the extent of motor pattern matching between observer and demonstrator in the performance of a given task (Galef et al., 1986; Heyes \& Dawson, 1990; Palameta \& Lefebvre, 1985).
Clearly, such studies are also needed for the hen. In our experiments, a number of specific points were of interest. First, the demonstrators were overtrained and never pecked an incorrect key during the observation sessions. It is known that pigeons are able to learn something from the observation of incorrect as well as correct responses (Biederman \& Vanayan, 1988), so response acquisition might have improved if less well trained demonstrators were used. The demonstrators were affected by the presence of observers since, on Day 1 in both experiments, keypeck responses were slower and demonstrators spent some time pecking the Perspex partition. This effect had largely vanished by Day 2 . The most obvious difference between demonstrators was in their mean speed of keypecking, but since there were no apparent differences between observers within similar groups that had observed different demonstrators, this seemed to have no effect.

In Experiment 1, observers were retested after a further observation session on Day 11. Since pecks on both keys were rewarded during the first test, it was possible that autoshaping would result in an increase in response rate on both keys and a decrease in discrimination ratio. If, however, birds paid more attention to the demonstrators on Day 11 after their exposure to the response chamber, then an increase in discrimination ratio might be expected. In fact, both response rates and discrimination ratios decreased on the second test. To draw serious conclusions on this point, further data would need to be collected, both from birds that had further observation experience after their first test and from birds that did not.

\section{REFERENCES}

Biederman, G. B., \& Vanayan, M. (1988). Observational learning in pigeons: The function of quality of observed performance in simultaneous discrimination. Learning \& Motivation, 19, 31-43.

Clayton, D. A. (1978). Socially facilitated behavior. Quarterly Review of Biology, 53, 315-318.

Cronhelm, E.(1970). Perceptual factors and observational learning in the behavioral development of young chicks. In J. Crook (Ed.), Social behaviour in birds and mammals: Essays on the social ethology of animals and man. New York: Academic Press.

Denny, M. R., Clos, C. F., \& Bell, R. C. (1988). Learning in the rat of a choice response by observation of S-S contingencies. In T. R. Zentall \& G. G. Galef (Eds.), Social learning: Psychological and biological perspectives (pp. 207-223). Hillsdale, NJ: Erlbaum.

Edwards, C. A., Hogan, D. E., \& Zentall, T. R. (1980). Imitation of an appetitive discriminatory task by pigeons. Bird Behaviour, 2, 87-91.

GALEF, B. G., JR. (1988). Imitation in animals: History, definition, and interpretation of data from the psychological laboratory. In T. R. Zentall \& G. G. Galef (Eds.), Social learning: Psychological and biological perspectives (pp. 3-27). Hillsdale, NJ: Erlbaum.

Galef, B. G., JR., Manzig, L. A., \& Field, R. M. (1986). Imitation learning in budgerigars: Dawson and Foss (1965) revisited. Behavioral Processes, 13, 191-202.

Heyes, C. M., \& DAwson, G. R. (1990). A demonstration of observational learning in rats using a bidirectional control. Quarterly Journal of Experimental Psychology, 42B, 59-71.

Johnson, S. B., Hamm, R. J., \& LeAhey, T. H. (1986). Observational learning in Gallus gallus domesticus with and without a conspecific model. Bulletin of the Psychonomic Society, 24, 237-239.

Palameta, B., \& Lefebvre, L. (1985). The social transmission of a food finding technique in pigeons: What is learned? Animal Behaviour, 33, 892-896.

Suboski, M. D., \& Bartashunas, C. (1984). Mechanisms for social transmission of pecking preferences to neonatal chicks. Journal of Experimental Psychology: Animal Behavior Processes, 10, 182-194.

VAllortigara, G., \& Zanforlin, M. (1988). Simultaneous discrimination learning in chicks: Spatial representations and object characteristics. Ethology, 79, 248-256.

ZAJONC, R. B. (1965). Social facilitation. Science, 149, 269-274.

Zentall, T. R., \& Galef, G. G. (1988). Social learning: Psychological and biological perspectives. Hillsdale, NJ: Erlbaum.

Zentall, T. R., Levine, J. M. (1972). Observational learning and social facilitation in the rat. Science, 178, 1220-1221.

(Manuscript received February 21, 1992.) 